\title{
Cracks in the RAC
}

\section{Washington}

LAST week, the US National Institutes of Health recombinant DNA advisory committee (RAC) approved what is billed as the first experiment in human gene therapy designed to immunize a cancer patient against his own tumour. But it rejected out of hand the recommendation of its own gene therapy subcommittee that it approve a protocol for the treatment of ovarian cancer with a genetically engineered "vaccine", a move that cast new doubts on the future of the subcommittee.

The RAC unanimously approved two protocols submitted by Steven Rosenberg of NIH's National Cancer Institute (NCI) that will be the first attempt to use gene therapy to find a cancer vaccine for melanoma. With no shortage of patients, Rosenberg began treatment on a 46-yearold man with metastatic melanoma within 24 hours of receiving RAC approval, followed immediately by approval from NIH director Bernadine Healy. Rosenberg first introduced the gene coding for tumour necrosis factor (TNF), a potent anti-tumour toxin, into a tumour cell line established from the patient. The gene-modified tumour cells were then injected back into the patient in the hope that they will be more immunogenic than unaltered tumour cells. In order to boost the hoped-for antitumour effect, lymphocytes will be withdrawn after 21 days from the patient, expanded or multiplied in the laboratory, and then be reinfused into the patient. Rosenberg's second protocol, almost identical in detail to the first, employs interleukin-2 instead of TNF. The RAC also approved the experimental therapy for patients with advanced colorectal and renal carcinomas.

But the ovarian cancer protocol, which was given the green light by the subcommittee, was shot down by the RAC in a 19 to 0 vote. In earlier in vitro experiments and in mouse studies, Scott Freeman of the University of Rochester Medical Center had demonstrated that transfer of the gene for herpes simplex virus-thymidine kinase into ovarian tumour cells renders the cells more sensitive to antiviral agents such as ganciclovir. Freeman had planned to apply this rationale to the treatment of patients with ovarian cancer who were in relapse and who had already received chemotherapy and radiation treatment.

William Kelley of the University of Pennsylvania Medical Centre, who sits on both the subcommittee and the RAC and who was a primary reviewer of the Freeman protocol, had strong reservations about the feasibility of the study but left before the vote was taken at the July subcommittee meeting. Kelley says he felt that a lot more work needed to be done before approval would be warranted and admits to being "very surprised" that approval had been granted.

Disagreement about the protocol centres on whether Freeman has obtained sufficient data from animal studies.

In addition to the focus on specific gene therapy protocols, the meeting generated a rising tide of opinion among committee members that the two-tiered review process (where protocols must first pass the subcommittee, then the full RAC) is unwieldy, involves considerable duplication of effort and sends confusing signals to researchers. Phasing out the human gene therapy subcommittee in the long term now seems inevitable.

In the early $1980 \mathrm{~s}$, the RAC had responsibility for a number of research areas, including experiments that involved the deliberate release of genetically engineered organisms. But as concerns about recombinant organisms have diminished, the purview of the RAC has diminished and its role has become almost parallel to that of the gene therapy subcommittee. The subcommittee was set up in the summer of 1984 in anticipation of a flood of research protocols involving somatic-cell gene transfer and gene therapy. Today, the RAC evaluates little else.

As someone who speaks from personal experience, having successfully steered one of the first protocols for gene therapy through a tortuous review process, W. French Anderson of NIH's Heart Lung and Blood Institute is an outspoken critic of the two-tiered NIH system. "The point is", Anderson says, "there really is no need for two separate committees" because the RAC itself now has time to review protocols in detail without prior subcommittee review. Anderson, with Rosenberg and Michael Blaese of NCI were the first to conduct a trial of gene transfer when they used a genetically engineered marker gene to track anti-tumour lymphocytes in patients with melanoma.

Henry Miller, who heads up the Office of Biotechnology within the FDA, agrees with Anderson and favours consolidation of the two committees. "Given that the full RAC has very little to occupy it other than gene therapy, it seems self-evident that it should and can reconstitute itself to be primarily concerned with gene therapy", says Miller, whose agency also reviews human gene therapy protocols.

In the short term, the RAC is attempting to streamline the review process to make it more efficient. And, although change is not expected overnight, a subcommittee has been appointed to consider whether the gene therapy subcommittee and the full committee should be merged. The new subcommittee on mergers has until February to reach an opinion.

Diane Gershon

\section{Approvals still slow, but pipeline full}

\section{Washington}

ONE hundred and thirty-two drugs and vaccines are now in development at US biotechnology companies, a 63 per cent increase since 1988 , according to a report released last week by the US Pharmaceutical Manufacturers Association (PMA) entitled "Biotechnology Medicines in Development". Of these, half are being tested for cancer, or cancer-related conditions.

But although the future clearly looks bright, biotechnology in the present is still more smoke than fire. Just three biopharmaceuticals have been approved by the US Food and Drug Administration (FDA) in the last 16 months, the date of the last PMA survey, and only 14 such biotechnology products have been approved over the last 9 years. Given this disturbing trend, the PMA has estimated that, at current staffing and funding levels, it would take the FDA 13 years to approve the 21 medicines already awaiting approval.

The US patent system is equally to blame in slowing biotechnology developments, PMA found. Although the patent office initiated a programme in 1988 to reduce the processing time of biotechnology patent applications, the average processing time of $\mathbf{2 5 . 6}$ months still lags far behind the 18-month average for all patent applications. Much of the reason for this is no doubt the 15 per cent annual growth rate in filings for biotechnology inventions - more than twice the average annual increase of 7 per cent in all patents.

The United States can, however, draw comfort from the fact that of the 169 genetic engineering health-care patents issued in 1990, 82 per cent were of US origin; Japan was second with 11 per cent.

D.G.

\section{ANTARCTIC OZONE}

\section{Worst hole yet}

\section{Washington}

Stratospheric ozone levels over Antarctica have reached the lowest levels on record, researchers monitoring a National Aeronautics and Space Administration (NASA) satellite reported last week. In its most recent pass over Antarctica, the Total Ozone Mapping Spectrometer (TOMS) aboard NASA's Nimbus 7 satellite recorded ozone levels of less than 120 Dobson units (a measure of atmospheric opaqueness to ultraviolet and other light), and tentative measurements as much as 10 units lower. That compares to measurements of 500 units in normal conditions. "The minimum ozone on October 6, 1991 [a 110 Dobson unit reading], is the lowest we have ever seen with the TOMS instrument in its 13-year record of data," said NASA researcher Arlin Krueger. C.A. 